1

\title{
Bioactivity of wollastonite/aerogels composites obtained from a TEOS-MTES matrix
}

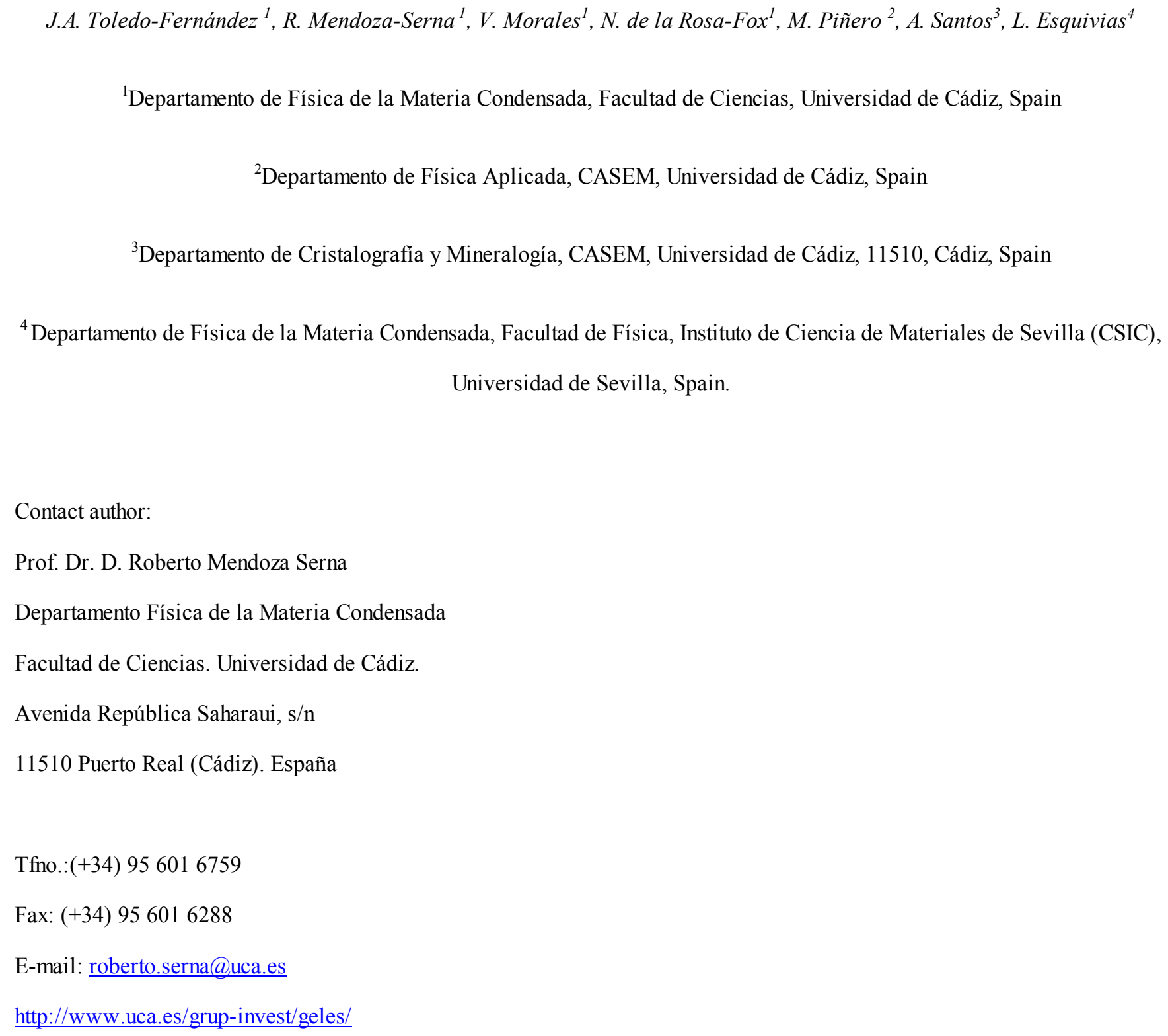




\begin{abstract}
Organic-inorganic hybrid materials were synthesized by controlled hydrolysis of tetraethoxysilane (TEOS), methyltrimethoxysilane (MTES), synthetic wollastonite powders and polydimethylsiloxane (PDMS) in an ethanol solution. Aerogels were prepared from acid hydrolysis of TEOS and MTES with different volume ratio in ethanol, followed by addition of wollastonite powder and PDMS in order to obtain aerogels with $20 \mathrm{wt} \%$ of PDMS and $5 \mathrm{wt} \%$ of CaO of the total silica. Finally, when the wet gels were obtained, they were supercritically dried at $260{ }^{\circ} \mathrm{C}$ and 90 bar, in ethanol. In order to obtain its bioactivity, one method for surface activation is based on a wet chemical alkaline treatment. The particular interest of this study is that we introduce hybrid aerogels, in a $1 \mathrm{M}$ solution of $\mathrm{NaOH}$, for $30 \mathrm{~s}$ at room temperature. We evaluate the bioactivity of TEOS-MTES aerogel when immersed in a static volume of simulated body fluid (SBF). An apatite layer of spherical-shaped particles of uniform size smaller than 5 microns is observed to form on the surface of the aerogels after 25 days soaking in SBF.
\end{abstract}

Keywords: organic-inorganic hybrid, aerogel, wollastonite, composite, bioactive materials, mechanical properties.

\title{
Introduction
}

Organic-inorganic hybrid materials (OIHM) obtained from tetraethoxysilane and methyltriethoxysilane (TEOS-MTES systems) have been extensively studied as matrices for different functional molecules. They offer many potential applications as porous films with low dielectric constant, hydrophobic membranes with very high gas permeability for $\mathrm{CO}_{2}$, and coatings with interesting mechanical properties $[1,2,3,4,5]$. OIHM obtained from TEOS, MTES and poly-dimethyl-siloxane (PDMS) present a lower porosity and higher rupture strength than TEOS-MTES gels, and can be used for their optical, electrical and catalytic properties [6].

Porous bioactive glasses are potentially useful materials for orthopaedic applications. Their porosity is an important characteristic since it allows vascular penetration and subsequent neo-bone growth. A high surface-to-volume ratio helps to make these materials biodegradable and bioactive, permitting an apatite-like layer to grow when in contact with body fluid [7].

Silica gels derived from the sol-gel process have a high surface area and porosity and have been shown to be far more effective in inducing hydroxyapatite formation than either silica glass or quartz [8]. The 
textural properties play a crucial role in governing the bioactivity of these materials. Silica aerogels are nanostructured, transparent, chemically inert and highly porous materials. The density of these aerogels may vary from $0.0019 \mathrm{~g} \cdot \mathrm{cm}^{-3}$ to $0.9 \mathrm{~g} \cdot \mathrm{cm}^{-3}$ [9], with a high porosity, close to $90 \%$, with pores of nanometric size that give rise to specific surfaces of between 600 and $1000 \mathrm{~m}^{2} \cdot \mathrm{g}^{-1}$, and their composition stays identical to that of vitreous silica $[10,11]$. Their main limitations are fragility and high hygroscopicity.

In recent years, organically-modified ceramics from gels have been attracting much attention as a new family of hybrid materials. In these materials, organic polymers are chemically incorporated into the inorganic network at the molecular level. As a result, unique mechanical properties can be derived, particularly a low elastic modulus and high ductility combined with high mechanical strength. It is widely believed that such hybrid materials present unique applications as a new kind of bioactive material [12].

Wollastonite is a natural calcium silicate, which has been used extensively as filler in polymers and cements, to fabricate composites with improved mechanical properties. Recent studies have shown that wollastonite is bioactive and degradable; consequently it has potential use as a bioactive material in tissue repair or tissue engineering research [13].

Different metal pre-treatment and coating methods, such as alkaline or acid treatment, or using $\mathrm{H}_{2} \mathrm{O}_{2}$, and sol-gel coating of $\mathrm{TiO}_{2}$, have been used by various research groups in an attempt to form such a bioactive surface on Ti plates. Kim et al. [14] reported that amorphous sodium titanate hydrogel, obtained by exposing pure Ti to an alkaline solution and subsequently to heat treatment, would induce apatite formation when soaked for a period of time in SBF. They showed that pure Ti metal formed a bonelike apatite layer on its surface in SBF within 3 days after being prepared, by soaking in a $5 \mathrm{M}$ solution of $\mathrm{NaOH}$ at $60^{\circ} \mathrm{C}$ for $24 \mathrm{~h}$ with subsequent heat treatment at $600^{\circ} \mathrm{C}$ for $1 \mathrm{~h}$ [15]. Other authors have reported that, in order to induce nucleation of the Ti with $1-20 \mathrm{M}$ solutions of $\mathrm{NaOH}$, it was exposed to temperatures of $60-95^{\circ} \mathrm{C}$ for $24 \mathrm{~h}$. In some cases it has been concluded that the immersion in a $5 \mathrm{M}$ solution of $\mathrm{NaOH}$ at $80^{\circ} \mathrm{C}$ for $24 \mathrm{~h}$ is the optimum treatment $[16,17]$. 
The objective of the present study is to synthesize hybrid bioactive aerogels, whose inorganic phase is $\mathrm{SiO}_{2}$ and the organic phase is PDMS and the methyl groups that remain bound to silicon after the MTES hydrolysis. Synthetic wollastonite powders are used as the bioactive phase. They received a surface treatment that induces the formation of the hydroxyapatite nucleus. This treatment consisted of maintaining the aerogels in an alkaline solution $(\mathrm{NaOH}, 1 \mathrm{M})$ at room temperature for $30 \mathrm{~s}$. Studies of the resulting bioactivity and mechanical properties were also carried out, and the results were compared with those for human cancellous bone to evaluate its potential application for bone substitution or regeneration.

\section{Materials and methods}

\subsection{Sample preparation}

Silica-based organic-inorganic hybrid gels were synthesized by the classic sol-gel method using a twostep procedure. First, TEOS and MTES (both reagents from Merck, Germany; purity $\geq 99 \%$ ), were used as inorganic and organic phase precursors, respectively. We have combined different amounts of TEOS and MTES, with the following TEOS:MTES volume ratios: 9:1, 5:5 and 1:9. They were hydrolysed under-stoichiometrically with acidic water $(\mathrm{pH} \sim 1)$ in a molar ratio $\left[\right.$ TEOS+MTES]: $\left[\mathrm{H}_{2} \mathrm{O}\right]=1: 0.84$. At this stage, $320 \mathrm{~J} \cdot \mathrm{cm}^{-3}$ of ultrasound was applied to the mix from a device delivering $0.6 \mathrm{w} \cdot \mathrm{cm}^{-3}$ of ultrasound power energy to the system, giving a transparent and homogeneous solution.

In the second step, silanol-terminated poly-dimethyl-siloxane (PDMS) with quoted average molecular weight of $400-700 \mathrm{~g} \cdot \mathrm{mol}^{-1}$ (ABCR, USA; $99.5 \%$ ) was used as the polymer component. This organic polymer was added (drop by drop, under the action of $320 \mathrm{~J} \cdot \mathrm{cm}^{-3}$ of ultrasound) in a molar ratio [TEOS]:[DMS] $=1: 0.027$ (representing $\sim 20 \%$ by weight of PDMS with respect to the final amount of silica), where the organic fraction has been expressed as a function of the dimethyl-siloxane monomer, DMS. Then the sol was left in an oven for $24 \mathrm{~h}$ at $50^{\circ} \mathrm{C}$. The mix was hydrolysed $(\mathrm{pH} \sim 1)$ with $\mathrm{HNO}_{3}$ catalyst (Panreac, Spain; purity $60 \%$ by vol.) in a molar ratio [TEOS]:[ $\left.\mathrm{H}_{2} \mathrm{O}\right]=1: 3.16$, again applying $320 \mathrm{~J}^{\mathrm{cm}} \mathrm{cm}^{-3}$ of ultrasound energy. Synthetic wollastonite powders $\left(\mathrm{CaSiO}_{3}\right)[9]$ were used as a bioactive phase. The appropriate amount of wollastonite (to give a Ca content of $5 \%$ by weight with respect to 
the total amount of silica) was dispersed in $75 \mathrm{ml}$ of $\mathrm{EtOH}$ per gram of wollastonite and then added to the precursor sol under sonication $\left(320 \mathrm{~J} \cdot \mathrm{cm}^{-3}\right)$. The mixture was poured into a polyethylene container before gelation, which occurs in approximately one minute, thus preventing the powder from settling. Then the container was left in an oven at $50^{\circ} \mathrm{C}$ for $24 \mathrm{~h}$. Next, the alkogels were soaked in ethanol at room temperature for 7 days for aging and removing the residual water from the pores.

At this point the gel is placed in an autoclave and the pore liquor is vented-off above the supercritical conditions of ethanol $\left(240^{\circ} \mathrm{C}, 63 \mathrm{bar}\right)$. The supercritical state is attained by slow heating $\left(1{ }^{\circ} \mathrm{C} / \mathrm{min}\right)$ in order to minimize the ethanol thermal expansion coefficient, which is much greater than that of the wet silica gel network. Then the heating produces the evaporation of the additional volume of ethanol that allows the supercritical pressure and temperature $\left(255^{\circ} \mathrm{C}, 85\right.$ bar) to be reached, in such a way that the vapour-liquid equilibrium curve is never crossed, to avoid capillary pressures on the adjacent pore. Thus the structure does not collapse and the aerogel retains its original shape. As a provision for the mechanical test, samples were made as cylinders of approximately $18 \mathrm{~mm}$ length and $8 \mathrm{~mm}$ diameter. Density was calculated by weighing the sample with a well-defined geometry.

In order to facilitate the bioactivity of aerogels, we applied an alkaline treatment to the surface of the samples, without damaging the material. In our case, we treated the aerogels with $\mathrm{NaOH}(1 \mathrm{M})$ for $30 \mathrm{~s}$ at room temperature. A porous surface layer adheres strongly to the aerogel, as the result of the increased number of $\mathrm{OH}$ terminating groups on the surface. It is well-known that the presence of $\mathrm{OH}$ groups seems to facilitate the bonding of the aerogel to the apatite layer. It was expected that the use of the alkaline treatment would makes the aerogel surface hydrophilic. This condition plays a very important role in the formation of the apatite. After this treatment, the samples were gently washed in distilled water and dried in a desiccator for $24 \mathrm{~h}$.

The composites were designated in the style S20Ca5x. The values 20 and 5 refer, respectively, to the PDMS and Ca content of the composite matrix; $\mathrm{x}$ indicates that the TEOS:MTES volume ratio is $\mathrm{x}:(10-$ $\mathrm{x})$.

\subsection{Bioactivity test}


In order to evaluate the bioactivity, the aerogels previously treated with $\mathrm{NaOH}$ were immersed in sterile polyethylene boxes containing $35 \mathrm{ml}$ of SBF (Table I) at $37{ }^{\circ} \mathrm{C}$ for 25 days according to the procedure proposed by Kokubo et al. [18]. The SBF was prepared by dissolving reagent grade $\mathrm{NaCl}$, $\mathrm{NaHCO}_{3}, \mathrm{KCl}, \mathrm{K}_{2} \mathrm{HPO}_{4} \cdot 3 \mathrm{H}_{2} \mathrm{O}, \mathrm{MgCl}_{2} \cdot 6 \mathrm{H}_{2} \mathrm{O}, \mathrm{CaCl}_{2}, \mathrm{Na}_{2} \mathrm{SO}_{4}$ in distilled water, and buffering the solution to $\mathrm{pH} 7.4$ with tris-hydroxymethyl-aminomethane $\left(\left(\mathrm{CH}_{2} \mathrm{OH}\right)_{3} \mathrm{CNH}_{3}\right)$ and $1.0 \mathrm{M} \mathrm{HCl}$ at $37{ }^{\circ} \mathrm{C}$. Then the aerogels were rinsed with distilled water and dried in a desiccator for $24 \mathrm{~h}$.

The Kokubo's solution contains the inorganic components of the human blood plasma in similar concentrations. Several authors report that in vitro experiments with Kokubo's solution can satisfactorily reproduce in vivo behaviour of implant materials [19].

\subsection{Examination of bioactivity and mechanical response}

Three composites were synthesized: S20Ca5M1, S20Ca5M5 and S20Ca5M9. They were characterized structurally and texturally, and their bioactive and mechanical behaviours were evaluated to study the influence of the MTES content on the performance of the composite.

The thermogravimetric (TG) study was carried out in a Setaram Setsys 1750 by heating the samples in air from $25{ }^{\circ} \mathrm{C}$ to $1000{ }^{\circ} \mathrm{C}$ at $10{ }^{\circ} \mathrm{C} / \mathrm{min}$. The average pore diameter and surface area of the composites were determined by $\mathrm{N}_{2}$ adsorption/desorption isotherms at $77 \mathrm{~K}$ carried out in a Sorptomatic 1990 unit (CE Instruments).

To evaluate the bioactivity, the formation of apatite-like layers on the sample surfaces was monitored by scanning electron microscopy (SEM) in a FEI Sirion electron microscope coupled to an EDAX Genesis system. The Fourier Transform Infrared (FTIR) spectra of the aerogels were recorded before and after soaking, using a Bruker Vertex70 spectrophotometer with a resolution of $4 \mathrm{~cm}^{-1}$ in the 2000 $400 \mathrm{~cm}^{-1}$ region. Pellets were prepared by grinding the samples in an agate mortar and then mixing the powder with anhydrous $\mathrm{KBr}$ in a weight ratio of $\mathrm{KBr}$ :sample=100:1.

The X-ray diffraction pattern (XRD) measurements were performed using a Bruker AXS D8 Advance diffractometer by the step-scanning method with $\mathrm{Cu} \mathrm{K} \mathrm{K}_{\alpha}$ radiation, a scan range from 20 to $50^{\circ} 2 \theta$, with a step of $0.2^{\circ}$, and a counting time of $1 \mathrm{~s}$ per step; the instrument was operated at $40 \mathrm{kV}$ and $40 \mathrm{~mA}$. 
The strains at failure of the aerogels were evaluated at room temperature under compression using an AG-I machine (Shimadzu); the Young's moduli were calculated from the slope of the initial linear elastic portion of the stress-strain curve. The S20Ca5M1 sample has been submitted to a creep test $[20,21]$ applying $1.00 \mathrm{MPa}$ for $4 \mathrm{~h}$ at room temperature. Creep compliance data were calculated directly, following the standard procedure [22,23], as the strain divided by the applied stress.

\section{Results and Discussion}

The thermograms of the S20Ca5M1, S20Ca5M5 and S20Ca5M9 samples are represented in Figure 1. The three composites present a sharp weight loss due to the carbonation of the organic polymer enduring after supercritical ethanol drying. The weight loss is greater in the S20Ca5M5 sample because the polymer is better encapsulated in the silica network formed by the TEOS and the MTES. This weight loss is $23 \%$ whereas for the S20CaM1 sample the loss is $16 \%$.

These materials exhibited characteristics of type IV and V isotherms (Figure 2) that correspond to mesoporous materials, in which the $\mathrm{N}_{2}$ adsorption at low pressure is produced by the formation of multiple layers. At high pressure, the adsorption is caused by capillary condensation, which is characterised by a clear hysteresis loop occurring in the mesoporous range. A transition is observed in the hysteresis loops from $\mathrm{H} 4$ to $\mathrm{H} 3$ type (which admittedly are quite similar) which indicates the presence of pores formed by flattened particles and slit-shaped pores [24]. The type H4 loop was reported for MCM-41 that exhibited particles with internal voids of irregular shape and broad size distribution (between 5 and $30 \mathrm{~nm}$ ) [25]. This loop seems to be due merely to the existence of mesopores formed by the organic phase embedded within the inorganic phase containing relatively few micropores. Microporosity is a characteristic of the silica aerogels prepared with ultrasounds (known as sonogels) [26], which is modified by the presence of the organic phase $[27,28]$. The textural properties extracted from the data analysis are given in Table II.

Figure 3 presents SEM images and EDS spectra of the surface of hybrid S20Ca5M1 after immersion in SBF for 25 days. A layer covers the surface (Figure 3a). As the magnification increases, rough spherical shaped particles can be observed (Figure $3 b$ and Figure 3c), formed by fine lamellar crystals (Figure 3d). 
A semi-quantitative yield analysis indicates a $\mathrm{Ca}$ to $\mathrm{P}$ ratio of 1.70 , almost the same composition as apatite $[29,30]$. The S20Ca5M5 and S20Ca5M9 samples did not show significant bioactivity.

The FTIR spectra of the S20Ca5M1 sample before and after soaking in SBF are shown in Figure 4a and Figure $4 \mathrm{~b}$, respectively. The bands at $450 \mathrm{~cm}^{-1}$ are characteristic of $\mathrm{O}-\mathrm{Si}-\mathrm{O}$ bending vibration [31]. The bands at 1268 and $803 \mathrm{~cm}^{-1}$ are assigned to $\mathrm{Si}-\mathrm{CH}_{3}$ bond of PDMS [32] and MTES [6,33], the band at $850 \mathrm{~cm}^{-1}$ is due to TEOS-PDMS copolymerization [34]. In Figure $4 \mathrm{~b}$, after soaking the composite for up to 25 days in SBF, the bioactive aerogel showed a typical doublet at 564 and $603 \mathrm{~cm}^{-1}$, which can be ascribed to $\mathrm{P}-\mathrm{O}$ bending vibration [35,36]. A specific peak of $\mathrm{HPO}_{4}{ }^{2-}$ [37] appears at 875 $\mathrm{cm}^{-1}$.

Figure 5 displays the diffracted X-ray intensities of the S20Ca5M1 composite after soaking in SBF for 25 days. The characteristic diffraction peaks of hydroxyapatite (HAp) were identified, confirming the bioactivity of this material $[38,39,40,41]$ in agreement with the SEM, EDAX and FTIR observations. Table III gives the values of both the Young's modulus and rupture strengths from the uniaxial compression test. The rupture modulus and Young's modulus increase as the content of MTES increases. For a better characterization of the visco-elastic behaviour of the material, we have calculated the Young modulus in three different intervals of the stress-strain curves: a) in the elastic range (strain between 0 and 0.10$), b)$ in the middle of the visco-elastic behaviour $(0.10-0.30)$ and, finally, c) near the rupture limit (0.30 - rupture strain). It can be seen that samples show an elastomer-like behaviour, as the Young's modulus increases as the strain approaches the rupture limit, attaining a value as high as 117 MPa for the S20Ca5M9 sample. The three types of samples studied in this work present values of the Young's and rupture modulus in the standard range for human cancellous bone, i.e. 50 - $500 \mathrm{MPa}[42$, 43].

A bi-exponential fitting of the creep compliance of the S20Ca5M1 sample was carried out and is represented in Figure 6. The satisfactory agreement between experimental data and theoretical expression indicates the existence of two different mechanisms of the time response. The exponents characterize the short-term and long-term responses. Their values are approximately $1500 \mathrm{~s}$ and $20000 \mathrm{~s}$, 
respectively, and the creep compliance value is close to $0.11 \mathrm{GPa}^{-1}$, quite similar to that of the pure silica aerogel measured by nanoindentation $\left(0.1 \mathrm{GPa}^{-1}\right)$ [44]. This can be explained on the basis of a response mechanism controlled by the inorganic phase skeleton.

\section{Conclusions}

The specific features of these hybrid aerogels: weight loss, specific surface and mechanical properties can be directly attributed to the MTES content. The treatment to induce bioactivity proved to be appropriate for obtaining bioactive materials. The aerogel $\mathrm{S} 20 \mathrm{Ca} 5 \mathrm{M} 1$ is expected to find application as a new type of bioactive material, having demonstrated an excellent apatite-forming ability in SBF, and mechanical properties analogous to those of human cancellous bone.

\section{Acknowledgement}

The authors express gratitude to the Spanish Ministerio de Educación y Ciencia and to the Consejería de Innovación Ciencia y Empresa of the Junta de Andalucía (Spain), (Projects MAT2005-01583 and TEP 790, respectively) for the financial support provided for this research. R. Mendoza-Serna is grateful to the U.N.A.M., DGAPA, México, for the scholarship supporting his sabbatical stay at the Departamento de Física de la Materia Condensada, Facultad de Ciencias, Universidad de Cádiz. 


\section{Figure captions}

Figure 1. TG curves of aerogels before soaking in SBF.

Figure 2. Nitrogen adsorption/desorption isotherms of aerogels.

Figure 3. SEM micrograph and EDS pattern of S20Ca5M1 aerogel after soaking in SBF for 25 days.

Figure 4. FTIR spectra of S20Ca5M1 aerogel after and before soaking in SBF.

Figure 5. X-ray powder diffraction patterns of aerogel.

Figure 6. Experimental creep compliance and biexponential fitting of sample S20Ca5M1 from creep test of $10 \mathrm{~h}$. 


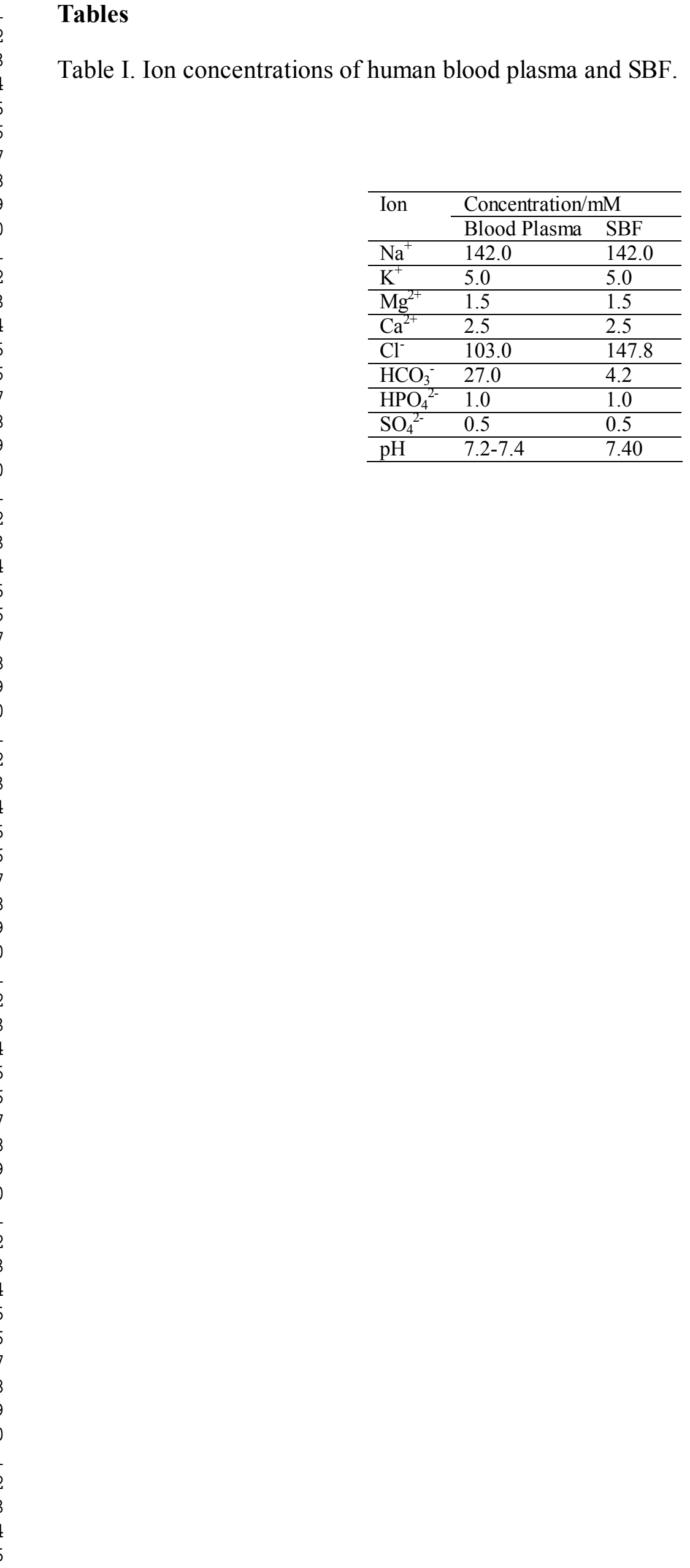


Table II. Textural data for the composites.

\begin{tabular}{llll}
\hline Aerogel & BET surface area $\left(\mathrm{m}^{2} / \mathrm{g}\right)$ & Pore volume $\left(\mathrm{cm}^{3} / \mathrm{g}\right)$ & Average pore diameter $(\mathrm{nm})$ \\
\hline S20Ca5M1 & 856 & 3.11 & 9.8 \\
\hline S20Ca5M5 & 582 & 1.02 & 7.5 \\
\hline S20Ca5M9 & 271 & 0.69 & 10 \\
\hline
\end{tabular}


Table III. Mechanical data for the composites.

\begin{tabular}{lllll}
\hline \multirow{2}{*}{ Sample } & $\begin{array}{l}\text { Rupture modulus } \\
(\mathrm{MPa})\end{array}$ & \multicolumn{4}{c}{ Young's modulus (MPa) } \\
\cline { 3 - 5 } & 4 & A & B & C \\
\hline S20Ca5M1 & 4 & 11 & 6 & 10 \\
\hline S20Ca5M5 & 5 & 29 & 38 & 61 \\
\hline S20Ca5M9 & 28 & 84 & 58 & 117 \\
\hline & \multicolumn{5}{c}{ Strain intervals (\%) } \\
& A: $0-10, \mathbf{B}:$ 10-30, C: 30 -Rupture
\end{tabular}




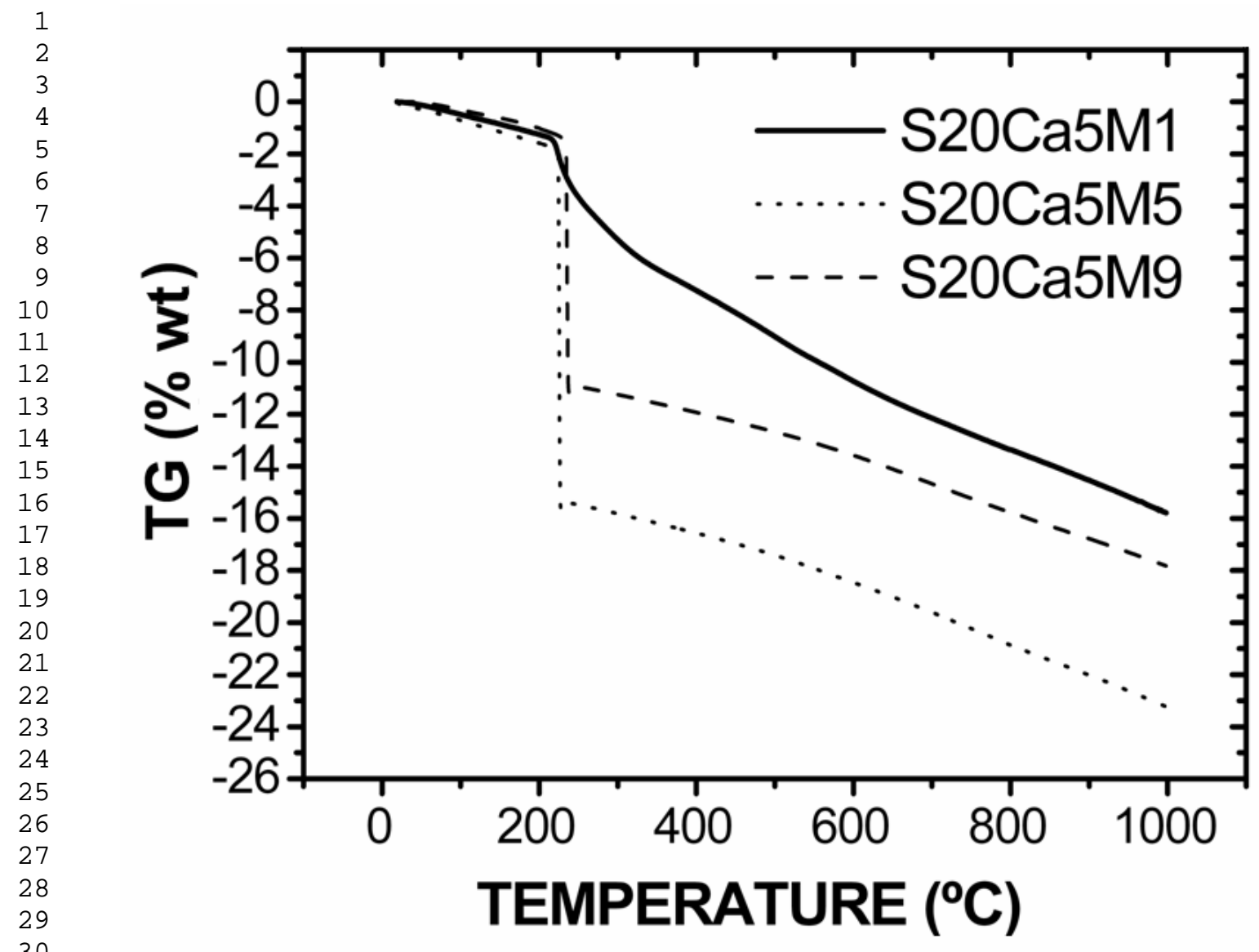

Figure 1. TG curves of aerogels before soaking in SBF. 


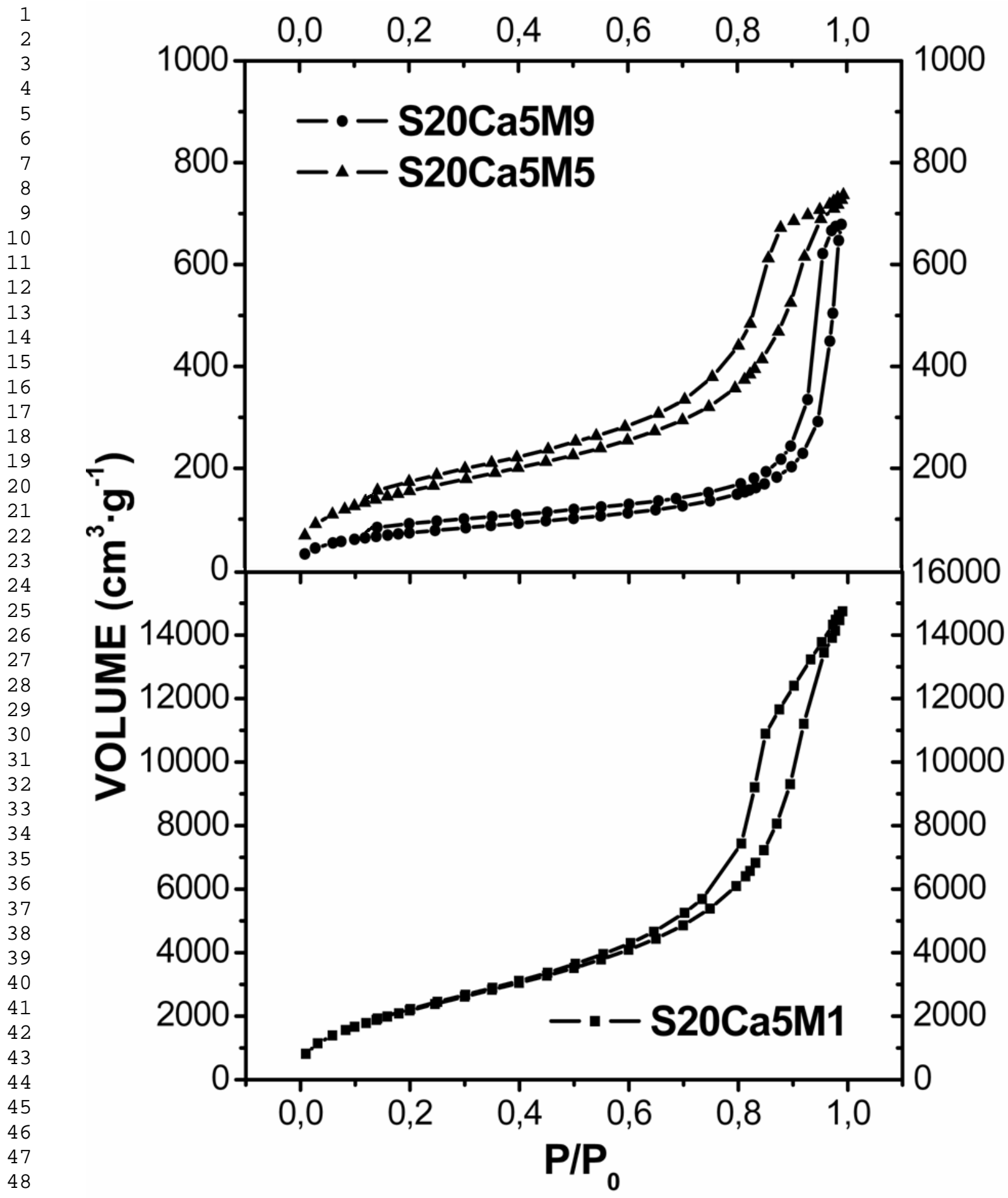



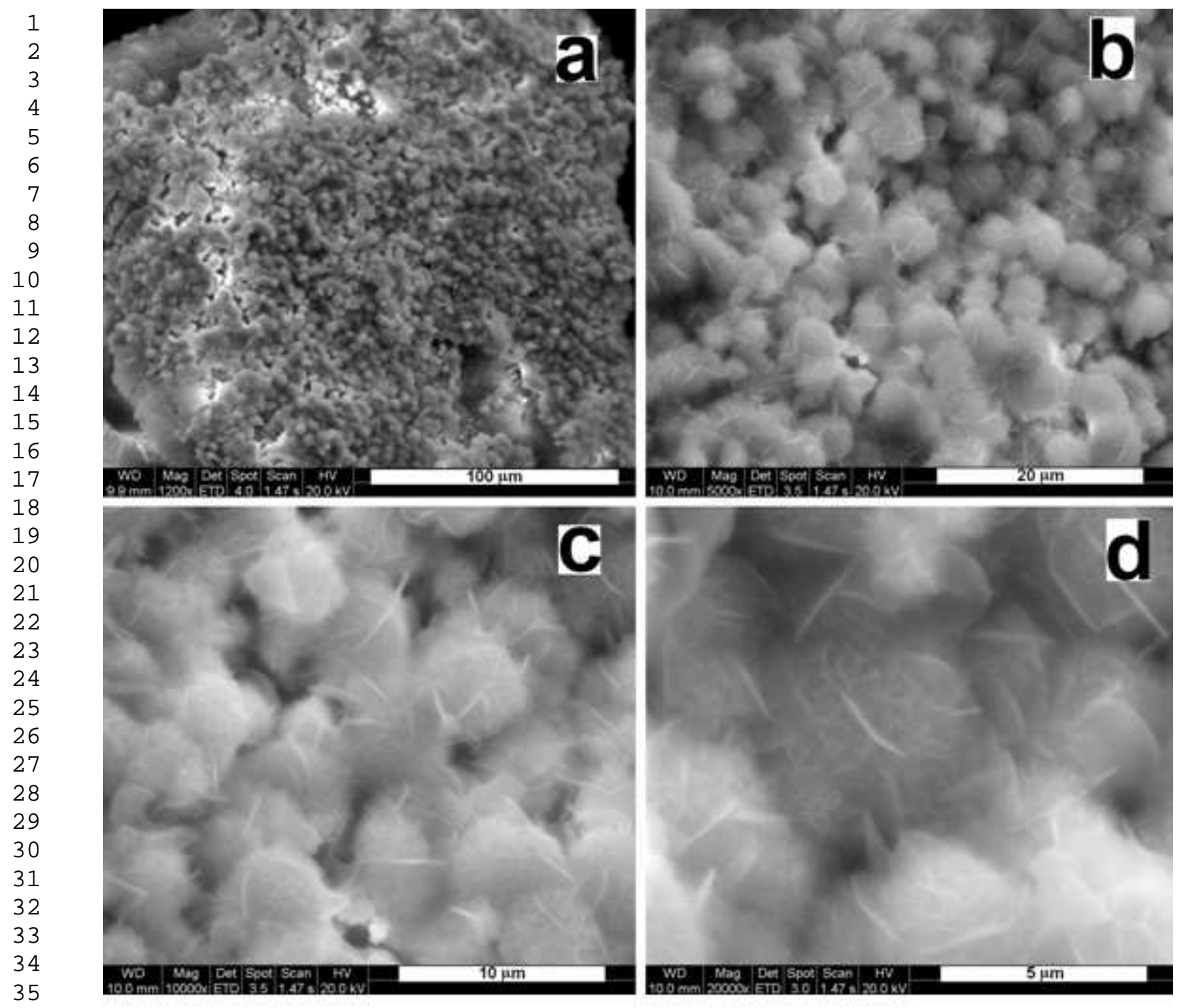


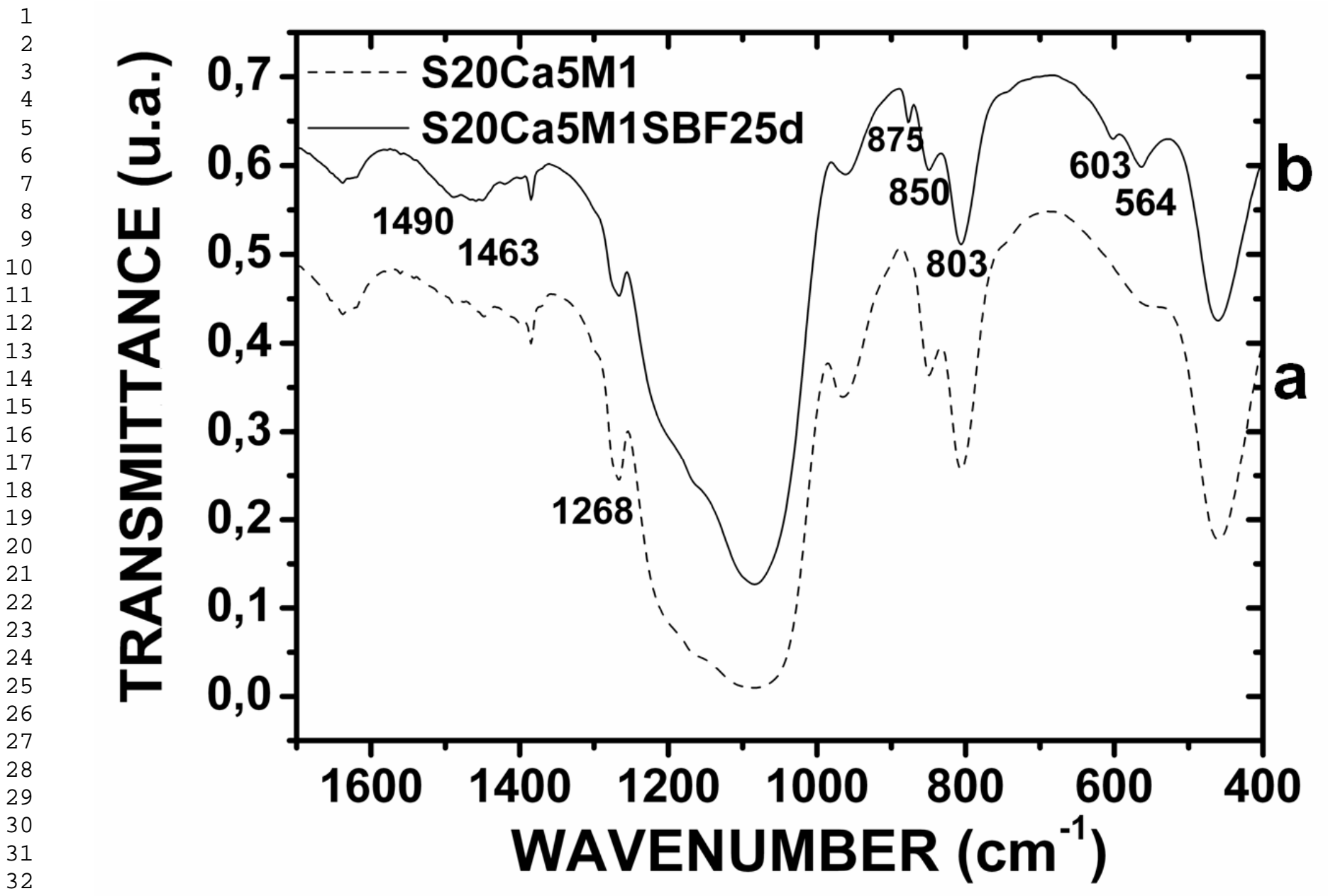

Figure 4. FTIR spectra of S20Ca5M1 aerogel after and before soaking in SBF. 


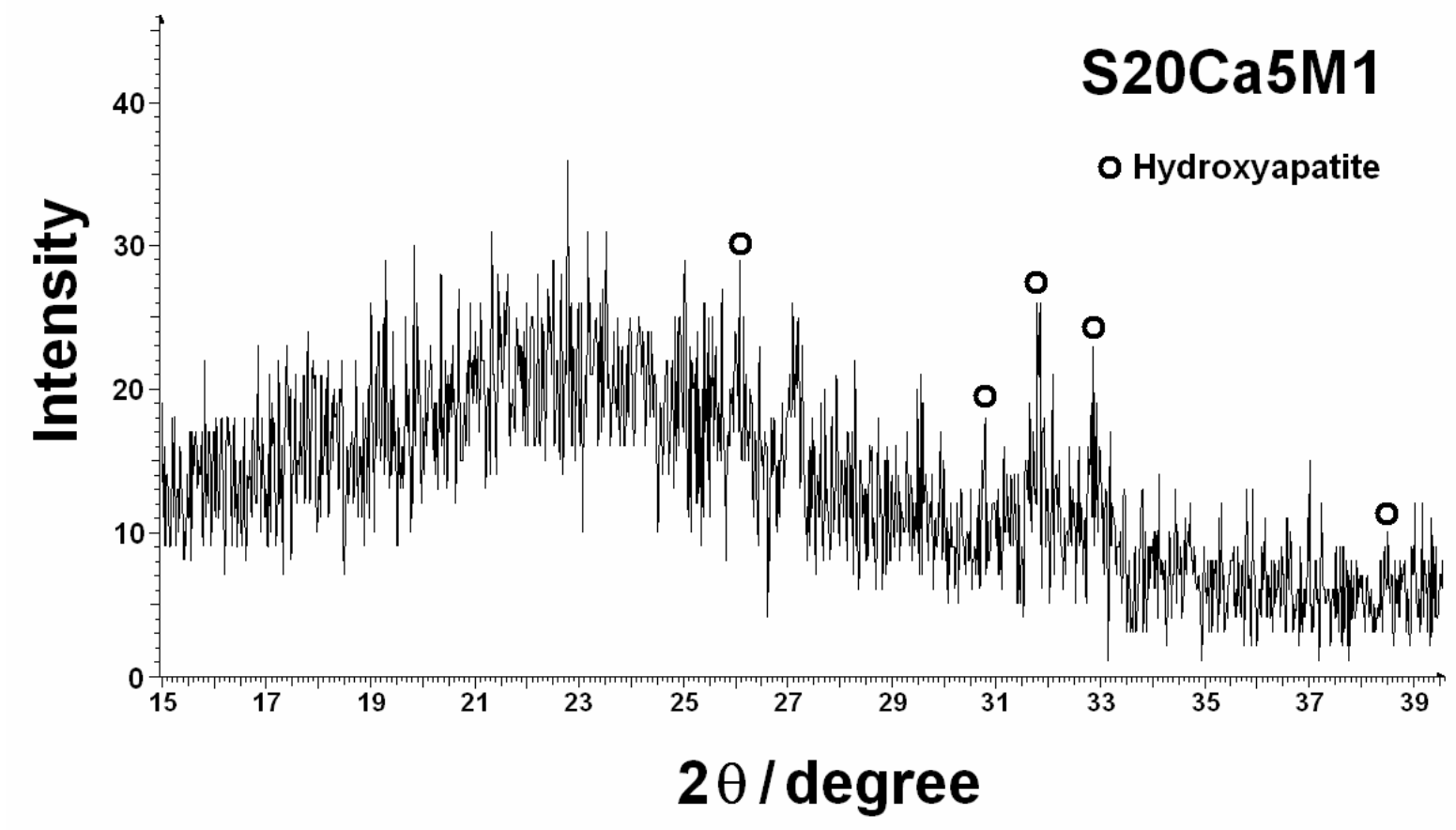

Figure 5. X-ray powder diffraction patterns of aerogel. 


\section{S20Ca5M1}

Adjustment of the bioexponential model:

$\mathbf{P 1 + P 2}{ }^{\star}\left(1-\exp \left(-\mathbf{x}^{*} \mathbf{P} 3\right)+\mathbf{P 4}^{*}\left(1-\exp \left(-\mathrm{x}^{*} \mathbf{P} 5\right)\right)\right.$

0.106

0.104

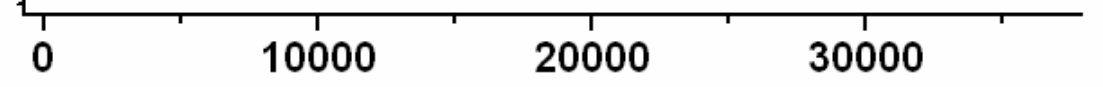

$\mathbf{t}(\mathbf{s})$

Figure 6. Experimental creep compliance and biexponential fitting of sample S20Ca5M1 from creep test of $10 \mathrm{~h}$. 


\section{References}

1. S. YU, T. K. S. WONG, X. HU and T. K. GOH, Thin Solid Films 462-463 (2004) 306.

2. R. GHISLENI, D. A. LUCCA, M. NASTASI, L. SHAO, Y. Q. WANG, J. DONG and A. MEHNER, Nucl. Instr. and Meth. B (2007), doi:10.1016/j.nimb.2007.01.061

3. R. M. DE VOS, W. F. MAIER and H. VERWEIJ, J. Non-Cryst Solids 158 (1999) 277.

4. N. K. RAMAN and C. J. BRINKER, J. Membrane Sci. 105 (1995) 273.

5. S. PELLICE, U. GILABERT, C. SOLIER, Y. CASTRO and A. DURAN, J. Non-Cryst Solids 348 (2004) 172.

6. Z. CHANG, L. AI'MEI, Z. XIAO, F. MIAO, H. JUAN and Z. HONGBING, Opt. Mater. (2006), doi:10.1016/j.optmat.2006.08.014

7. Â. L. ANDRADE, P. VALERIO, A. M. GOES, M. F. LEITE and R. Z. DOMINGUES, J. NonCryst Solids 352 (2006) 3508.

8. R. VITALA, J. SIMOLA, T. PELTOLA, H. RAHIALA, M. LINDEN, M. LANGLET and J. B. ROSENHOLM, J. Biomed. Mater. Res. 54 (2001) 109.

9. J. A. TOLEDO-FERNÁNDEZ, R. MENDOZA-SERNA, V. MORALES-FLÓREZ, N. DE LA ROSA-FOX, A. SANTOS, M. PIÑERO and L. ESQUIVIAS, Bol. Soc. Esp. Ceram. V. 46 [3] (2007) 138.

10. J. FRICKE and T. TILLOTSON, Thin Solid Films 297 (1997) 212.

11. N. HÜSING and U. SCHUBERT, in “Aerogels-Airy Materials: Chemistry, Structure and Properties", (Angew. Chem. Int., German, 1998) p. 22.

12. Q. CHEN, F. MIYAJI, T. KOKUBO and T. NAKAMURA, Biomaterials 20 (1999) 1127.

13. H. LI and J. CHANG, Biomaterials 25 (2004) 5473.

14. H. M. KIM, F. MIYAJI, T. KOKUBO and T. NAKAMURA, J. Ceram. Soc. Jpn. 105 (1997) 121.

15. M. WEI, H.-M. KIM, T. KOKUBO and J.H. EVANS, Mat. Sci. Eng. C 20 (2002) 125.

16. J.-H LIN, C.-H. CHANG, Y.-S. CHEN and G.T. LIN, Surf. Coat. Technol. 200 (2006) 3665. 
17. M. UCHIDA, H.-M. KIM, F. MIYAJI, T. KOKUBO and T. NAKAMURA, Biomaterials 23 (2002) 313 .

18. T. KOKUBO and H. TAKADAMA, Biomaterials 27 (2006) 2907.

19. K. TSURU, C. OHTSUKI, A. OSAKA, T. IWAMOTO and J. D. MACKENZIE, J. Mater. SciMater. M. 8 (1997) 157.

20. J. D. FERRY, in "Viscoelastic Properties of Polymers", 3rd Ed. Wiley, New York (1980).

21. S. B. ADALJA and J. U. OTAIGBE, Polymer Composites, 23 (2002) 171.

22. H. LU, B. WANG, J. MA, G. HUANG and H. VISWANATHAN, Mechanics of The TimeDependent Materials, 7 (2003) 189.

23. M. R. VANLANDINGHAM, J. S. VILLARUBIA, W. F. GUTHRIE and G. F. MEYERS, Macromolecular Symposia 167 (2001) 15.

24 M. KRUK and M. JARONIEC, Chem. Mater. 13, (2001) 3169.

25. H.-P. LIN, S.-T. WONG, C.-Y MOU and C.-Y Tang, J. Phys. Chem.B 104 (2000) 8967.

26. L. ESQUIVIAS and N. DE LA ROSA-FOX, J. Sol-Gel Sci. \& Technol. 26 (2002) 651.

27. N. DE LA ROSA-FOX, L. ESQUIVIAS and M. PIÑERO, 'Organic-Inorganic Hybrid Materials from Sonogels' in "Handbook of Organic-Inorganic Hybrid Materials and Nanocomposites" (Vol. 1) Ed. S.H. NALWA. American Scientific Publishers, Ca., (2003) 241-270.

28. V. MORALES-FLÓREZ, “Modelos Estructurales y Propiedades Mecánicas de Aerogeles Híbridos" Ph. D Thesis, University of Seville (Spain), (2007).

29. X. LIU, CH. DING and P.K. CHU, Biomaterials 25 (2004) 1755.

30. X. LIU, CH. DING and Z. WANG, Biomaterials 22 (2001) 2007.

31. P. SARAVANAPAVAN and L. L. HENCH, J.Non-Cryst. Solids, 318 (2003) 1.

32. T. YABUTA, K. TSURU, S. HAYAKAWA and A. OSAKA, J Sol-Gel Sci Techn. 31 (2004) 273.

33. C. D. VOLPE, S. DIRÉ and E. PAGANI, J. Non-Cryst Solids 209 (1997) 51. 
34. M. FUKUSHIMA, E. YASUDA, H. KITA, M. SHIMIZU, Y. HOSHIKAWA and Y. TANABE, in "Proceedings of the $29^{\text {th }}$ International Conference on Advanced Ceramics and Composites-Advances in Bioceramics and Biocomposites”, edited by M. MISUNO (2005) p. 103.

35. R. O. R. COSTA, M. M. PEREIRA, F. S. LAMEIRAS and W. L. VASCONCELOS, J. Mater. Sci.-Mater. M. 16 (2005) 927.

36. M. MANZANO, A. J. SAlinAS and M. VAllET-REGí, Prog. Solid State Ch. 34 (2006) 267.

37. Y. R. DUAN, Z. R. ZHANG, C. Y. WANG, J. Y. CHEN and X. D. ZHANG, J. Mater. Sci.-Mater. M. $16(2005) 795$.

38. A. RÁMILA and M. VALLET-REGÍ, Biomaterials 22 (2001) 2301.

39. M. KAMITAKAHARA, M. KAWASHITA, N. MIYATA, T. KOKUBO and T. NAKAMURA, $J$. Mater. Sci.-Mater. M. 13 (2002) 1015.

40. M. P. MAHABOLE, R. C. AIYER, C. V. RAMAKRISHNA, B. SREEDHAR and R. S.

KHAIRNAR, Bull. Mater. Sci. 28 (2005) 535.

41. S. PADILLA, J. ROMÁN, A. CARENAS and M. VALLET-REGÍ, Biomaterials 26 (2005) 475.

42 L. L. HENCH and J. WILSON in "An Introduction to Bioceramics", edited by L. L. HENCH and J. WILSON (World Scientific, Singapore, 1993), p. 12.

43. T. KOKUBO, H.-M. KIM and M. KAWASHITA, Biomaterials 24 (2003) 2161.

44. N. DE LA ROSA-FOX, V. MORALES-FLÓREZ, J. A. TOLEDO-FERNÁNDEZ, M. PIÑERO, R. MENDOZA-SERNA and L. ESQUIVIAS, J. Eur. Cer. Soc. 27 (2007) 3311. 